\title{
Routinised heating system installation: the immutability of home heating
}

\author{
Faye Wade
}

Received: 8 October 2019 / Accepted: 17 April 2020 / Published online: 1 May 2020

(C) The Author(s) 2020

\begin{abstract}
Space heating is the largest contributor to domestic energy consumption in the UK (UK). Gas central heating systems usually extend into every room of a property, but often sit in the background of the lives of those using them. Installation could offer a critical moment to optimise the operating efficiency of these systems, or consider alternative low carbon technologies. However, whether installation acts as one such moment of change is currently unknown. Using ethnographic data collection, and the concepts of translation and interessement from Actor-Network Theory, this paper explores the tensions between existing sociotechnical arrangements and the new system components taking their position in the home. Installers are found to be subject to competing requirements from industry guidance and regulation, new system components and existing domestic configurations. A process of negotiation and compromise is revealed. This results in 'likefor-like' installations and heating system components being squeezed into spaces and hidden away. These efforts to maintain the status quo reinforce the immutability of domestic heating, restrict opportunities to fit alternative low carbon technologies and limit possibilities to reduce domestic energy consumption.
\end{abstract}

Keywords Domestic central heating · Installation ·

Actor-network theory · Ethnography

F. Wade $(\bowtie)$

Sociology, University of Edinburgh, 2.27 Chisholm House, High School Yards, Edinburgh EH1 1LZ, UK

e-mail: faye.wade@ed.ac.uk

\section{Introduction: the need to focus on domestic heat}

Under the 2008 Climate Change Act, the UK Government set a legally binding target to reduce greenhouse gas emissions to $80 \%$ of 1990 levels, by 2050 (HM Government 2008), and this has recently been revised to 'net zero' by 2050 (HM Government 2019a). Within the UK, there are more than 27 million dwellings (ONS 2014a), and space heating accounts for approximately $65 \%$ of household energy consumption (DBEIS 2019). The majority of UK homes have a gas central heating system which uses a boiler to heat water that is then transported around the home via a network of pipes and radiators. There are approximately 1.2 million new boilers still installed every year in England (HM Government 2018). Thus, despite efforts to shift towards lower carbon technologies, gas boilers are still the prevalent heating technology fitted in UK homes.

There have been numerous policies to reduce domestic heat consumption; these largely stem from a technocentric understanding of how to improve the efficiency with which installed central heating systems operate. For example, in 2005, the UK Government introduced the requirement for all newly installed boilers to be condensing; the required SEDBUK ${ }^{1} 2009$ efficiency rating is now $88 \%$ (DCLG 2013). In addition, Part $\mathrm{L}^{2}$

\footnotetext{
${ }^{1}$ The Seasonal Efficiency of Domestic Boilers in the UK (SEDBUK) is calculated for every model of boiler through laboratory testing. It is an estimate of average annual efficiency that provides a fair comparison of the energy performance of different boilers (BEPA 2014).

${ }^{2}$ Part L of the Building Regulations states that 'reasonable provision shall be made for the conservation of fuel and power in buildings' (HM Government 2010: 39).
} 
of the Building Regulations stipulates that fixed building services must 'have effective controls' (HM Government 2010: 39), and further technical efficiency improvements were sought with the introduction of the Boiler Plus standard in 2017 (HM Government 2017). In addition, there is a recognised need to upskill the workforce to achieve low carbon goals. Attempts to deliver this focus on developing standards that tradespeople are expected to comply with. In particular, heating installers must be Gas Safe registered (Wade et al. 2016a) and, where involved in installing technologies for holistic property retrofit, PAS 2030 compliant $^{3}$ (BSi 2019). Despite these attempts to ensure the quality and energy performance of heating installations, the energy consumed through space heating has not reduced at the rate needed to achieve climate goals. One failing of these strategies is their lack of consideration of how central heating systems are installed in the home and how this might contribute to subsequent operating energy efficiency.

In addition, policy makers are working towards the implementation of alternative heating technologies in homes. The UK Government's Clean Growth Strategy (2018) identifies the need to decarbonise heat, including the suggestion to 'build and extend heat networks across the country' (HM Government 2018: 13). It also highlights the need to 'futureproof' new homes for lowcarbon heating systems (HM Government 2018: 13), but remains vague on exactly how such futureproofing might be achieved, or what these alternative systems might be. Proposed pathways to 2050 include the use of combined heat and power units, heat pumps, or hydrogen to heat homes, and the installation of district heating (CCC 2019). All of these systems require quite different socio-technical arrangements to those in place for a domestic gas central heating system. For example, a district heating network works most efficiently with lower return temperatures. This may elicit the need for larger radiators than those currently in place, and occupants accepting lower output temperatures than those achieved through gas heating. Alternatively, a hydrogen network may not be compatible with the existing copper pipework that transports natural gas for a central heating system, and its success will be reliant on overcoming

\footnotetext{
${ }^{3}$ PAS 2035 covers how to assess dwellings for retrofit, including assessment, design and monitoring. PAS 2030 was updated in 2019 to sit alongside PAS 2035, with a focus on the installation, commissioning and handover of retrofitting works (BSi 2019).
}

consumer concerns about the safety of hydrogen. Understanding the routinised retrofitting of gas central heating systems could be helpful for informing such future initiatives. Despite this, the extent to which the installation and upgrade of conventional gas central heating systems creates space to develop readiness for alternative technologies (for example larger radiators and different controls) is yet to be explored.

This paper consequently asks what are the sociotechnical negotiations that currently take place during the installation of a gas central heating system? The paper proceeds by detailing the immutability of heating systems and introducing heating installers as middle actors responsible for the installation process. Actornetwork theory, including concepts of translation and interessement, is then introduced, alongside the ethnographic approach used for data collection. The results section considers how these ideas play out as new technologies take their place, old arrangements vie for attention, and actions are taken to ensure equivalence. The discussion and conclusions then consider the contribution of these findings to understanding domestic heating installation and their implications for future research and low-carbon heat policy.

\section{Literature review}

The immutability of home heating

By the time gas central heating systems entered the domestic market in the mid-1940s, coal fires were already deeply integrated into English homes (Arapostathis et al. 2013). Whilst coal fires could be viewed as a meeting point for the family (see Orwell 1945 for example), with gas central heating systems 'gone is huddling around the fire in a household's one heated room: in its place stands the potential for all day heating throughout the home' (Palmer and Cooper 2013: 46). Approximately 79\% of all households in England and Wales ${ }^{4}$ now have gas central heating systems (ONS 2014b). They make it possible to heat the whole home with little notice and for short periods of time, and do not require the active maintenance and

\footnotetext{
${ }^{4}$ The UK is made up of four separate countries: England, Scotland, Wales, and Northern Ireland. As such, certain powers and activities are devolved to the different countries. The census data cited only covers England and Wales; Scotland and Northern Ireland collect this data separately.
} 
physical re-fuelling of their coal counterparts. Historical accounts suggest that it is the delegation of the work and control of heat to a domestic gas infrastructure that has resulted in the spreading of space heating to the whole home and across different time frames (Kuijer and Watson 2017). For example, rather than embers dwindling and eventually dying out in a hearth, heat can now be 'turned down' when a person is asleep and quickly revived in the morning (Kuijer and Watson 2017). Despite the gas boiler's potential to offer flexible and varied timings and temperature settings, use of these systems is remarkably similar across the UK. Cluster analysis identified only four temperature profiles for English living rooms: a steady rise, a steep rise, a fairly consistent temperature throughout the day, and a schedule with two on-off settings per weekday (Huebner et al. 2014). In addition, a study in this journal of heating controller settings for 337 UK homes found synchronicity in demand, with a shared morning and evening peak across most dwellings, and shared participant expectations of when the heating will be on and off (Hanmer et al. 2019). In developing such know-how for the management of heat in the home, Royston notes that 'when people are exposed to a particular technology they may absorb or internalise a sense of its normality, creating an enduring disposition to use it' (Royston 2014: 155).

Indeed, ideas of keeping warm, and the technologies and practices associated with doing so, are embedded in the socio-technical arrangements of everyday life (Shove 2003). In addition, specific technological arrangements, such as radiators and thermostats, can underpin ideas of appropriate ways to keep warm (GramHanssen 2010a). For example, the maintenance requirements of wood-based heating have been found to deliver a certain degree of temporal structuring and feelings of satisfaction to those using them (Jalas and Rinkinen 2016). Once these ideas are embedded, they can be difficult to change (Gram-Hanssen 2010b). However, moving house or installing new devices could act as opportunities to alter embodied understandings of heating technologies and their use (Royston 2014). During such disruption, a new technology comes to be physically embedded in the property, and household practices and the role of technologies within them are negotiated. Despite this, a study of the domestication of air source water heat pumps found that they are assimilated into existing socio-technical contexts, rather than being adopted in the way intended by designers (Judson et al. 2015: 46). This is based on interviews and energy tours with householders after installation, and exactly what happens during the process remains unclear.

Why installation matters

Individuals including architects (Janda 1999), builders (Killip 2013), and plumbers (Bowden et al. 2012) have been found to have a significant role in shaping domestic energy consumption. Such actors have been conceptualised as 'middle actors', or agents of change that are able to influence those they work amongst. According to this 'middle-out perspective', these actors influence upstream to policy makers and industry, sideways to those in their profession or operating in a similar area, and downstream, to customers and householders (Parag and Janda 2014; Janda et al. 2014). For example, with regard to technology selection, tradespeople can apply their own ideas in shaping decisions about what gets installed in homes (Owen et al. 2014). Instead of offering a range of options, professionals might choose those that are more familiar to them. Such middle actors can also act as crucial 'conduits for information', advising and facilitating the choices of others (Schiellerup and Gwilliam 2009).

In keeping with this, the types of heating technology in homes, and the distribution of these, have been shaped over time by such middle actors and industry networks. An exploration of the journey from open hearth to central heating in America demonstrated that the networks in which consumers are positioned can be hugely influential to the uptake of new domestic heating technologies (Schwartz Cowan 1989). Such networks, including actors within the production, wholesale, and retail sectors, affect the willingness of consumers to purchase new heating products as they enter the market (Schwartz Cowan 1989). This is supported by a historiography of the introduction of the cast iron stove in America, which highlights the active role of the heating industry in finding a place for these new technologies within existing ways of life (Harris 2008). Later, in the UK, the gas industry and oil companies promoted the use of gas for central and space heating as a way to increase their customer base (Arapostathis et al. 2013). In this transition, 'lady demonstrators' had a particularly significant 'downstream' influence through encouraging the domestication of gas appliances as suitable for cooking (Clendinning 2000). These studies all demonstrate the larger networks responsible for shaping 
domestic heating technologies, including policy, sales teams and strategies, and gas infrastructures.

In keeping with this, heating installers influence how a central heating system takes shape; they must simultaneously recognise the agency of individual system components and negotiate with the requirements of the clients and the properties in which they work. These actors have been found to operate within a community of practice. For the preservation of this community and their membership within it, heating installers can maintain their expert status by selecting familiar products and making assertive decisions about what to fit (Wade et al. 2016a). However, the process of installation within this network is still unclear. Thinking about the replacement of contemporary heating systems, it has been suggested that

'For [the] replacement of heating systems in existing housing, it is clear that decisions about the appropriate system type and make or model are generally left to the installer...[who is]...usually able to suggest more or less what he sees fit.'

(Banks 2000a: 8.10)

Although this evidence indicates that heating installers are highly influential in shaping the central heating technologies installed in homes, Banks' study was carried out in the context of the introduction of new condensing boilers (prior to legislation enforcing thissee section 1). Although condensing boilers operate with a higher efficiency than their non-condensing counterparts, this does not guarantee the optimised performance of the system. The installer is still responsible for designing and sizing the system such that it can meet the heat load of the property, it is not over-sized and thus operating at lower efficiency, and the use of condensing mode can be maximised (CIBSE 2013). In particular, size-for-size replacement of existing boilers and radiators is not recommended, because the thermal properties of the dwelling may have changed (for example, increased insulation and more thermally efficient windows) and the original sizing is not always correct (EST 2008). Despite this, there has been little consideration of the realities of heating installation since Banks' study, whether installers are in fact able to install whatever 'they see fit', or how this might influence heating energy efficiency.

This makes it especially critical to consider the process of implementing a new central heating system, particularly whether this presents any opportunities for flexibility and change. This paper applies an approach informed by actor-network theory, particularly the concepts of translation and interessement, in order to illuminate the socio-technical negotiations that take place as these middle actors perform their work. These ideas are helpful for exploring the interactions between new technologies, older system components, and installers tasked with bringing them together in their middle actor role.

\section{Actor-network theory}

ANT posits that the social is not a 'thing amongst other things', instead it is a 'type of connection', and a study of the social should be considered as the 'tracing of associations' (Latour 2005: 5) between human and non-human actors. The idea emerged through detailed exploration of how scientific facts are built (Latour and Woolgar 1979), interrogation of the symmetry between fishermen, technologies, and scallops (Callon 1986a), the development and use of electric vehicles (Callon 1986b); and the fluidity of community water pumps (de Laet and Mol 2000), to name a few. Through the ANT lens then, installer practices both shape, and are very much shaped by, the technologies and physical things that form a part of them. By tracing the patterns of these relations embedded in practice, ANT observes the power of these practices and recognises that, in principle, alternatives are possible (Law and Singleton 2014: 380). Law (1992) highlights that humans form social networks through their interaction with other humans and also materials. Critically, he suggests that 'just as human beings have their preferences - they prefer to interact in certain ways rather than others - so too do the other materials that make up the heterogeneous networks of the social' (Law 1992: 382). Thus, interrogating home heating requires understanding 'the complex and dynamic processes through which heat is generated, transmitted, contained, and released, and of the roles played by numerous material elements.' (Royston 2014: 156).

ANT helps in recognising the relational nature of the seamless webs in which heterogeneous elements (such as people, technologies, buildings, and energy) interact (Hughes 1986). ANT has been used to propose the network of actors implicated in the specification of heating equipment (Banks 2000a, b) and to analyse the 
'products, practices and processes' of small and medium enterprises (SMEs) in the UK construction industry (Killip 2013). The concept has also been applied to understand the broader role of gas infrastructures, market actors, and policies in the transition to gas central heating systems (Hanmer and Abram 2017). Although these studies identify a role for a variety of human and non-human actors in shaping design decisions, they rely on interviews and document analysis away from the scenes of negotiated system installations and do not capture the active role of the installer or system components in these.

Although early ANT adopted a 'generalised symmetry', considering human and non-human actors as equivalent, it has been suggested that there is a need to incorporate the expertise and interests of different human actors into ANT analyses (Singleton and Michael 1993). Considering the varied agency of the different networked actors, 'system builders' have been identified as critical for coordinating different people and things to help create a 'single central vision' in the development of electricity networks (Hughes 1979). Similarly, in analysing the design of the bubble chamber, Pickering highlights the intentionality of the physicist that developed it, noting that 'he did not assemble bits and pieces of apparatus in the laboratory just for its own sake; he had an end in view' (1993: 557). The agency of such actors has been recognised through the notion of scripting, which suggests that technology designers and developers 'define the identity of putative users and set constraints on their likely future actions' (Woolgar 1991). The ways in which installers script end users in the selection and explanation of heating controls has been recognised (Wade et al. 2016b). However, the extent to which installers' agency shapes the negotiation of system components as they take their place in the home has not been considered. In this process, there is a need to manipulate and negotiate various different components to form a single system; two concepts are particularly useful for considering this: translation and interessement.

Processes of translation and interessement

Translation is a process whereby 'the identity of actors, the possibility of interaction and the margins of manoeuvre are negotiated and delimited' (Callon 1986a: 203). In this process, different actors and their varying interests are enrolled to function together within the network, and so 'actors define one another in interaction' (Callon 1991: 135). Thus, the heating system can only function because of the interconnectivity between the gas network, regulations regarding technical requirements, radiators, and the boiler, to name a few. However, the ordering and alignment of these devices is uncertain; there may be resistance from particular actors and attempts to enrol different entities can fail. Examining this alignment and viewing stability as the product of enrolment into a network can be helpful for understanding why some systems are more stable than others (Hanmer and Abram 2017).

Nyborg and Røpke (2015) draw on the notion of translation to explore the historical development of heat pumps in Denmark, noting that the durability of new actor configurations will be critical for their success. They suggest that intermediaries such as industry professionals can act as 'prime movers' in interessement, or implementing a program of action for enrolling different actors (Nyborg and Røpke 2015). Interessement is intended to capture interpretations of what 'yet-to-beenrolled actors are and want as well as with which entities these actors are associated' (Callon 1986a: 65). This may involve creating allegiances between actors and recognising actors that may support or resist the formation of the network, thus allowing for the identification of the bundle of links which unite a network (Akrich et al. 2002). A successful installation can be defined as one which generates sufficient commensurability between different components for them to align and form an operating system (Callon 1991).

\section{Stabilisation}

Within ANT, when a socio-technical network becomes stabilised to the extent that it is recognised as a single, coherent entity, it is black boxed (Callon and Law 1997). The term black box is taken from cyberneticians who use it 'whenever a piece of machinery or set of commands is too complex. In its place they draw a little box about which they need to know nothing but its input and output' (Latour 1987: 2-3). The term allows systems or devices to be considered only according to their inputs and outputs, with little need for understanding what takes place inside the black box (Winner 1993). Latour (1987: 4) suggests that scratching the recent history of any black box usually reveals 'uncertainty, people at work, decisions, competition, controversies'. He suggests that the task of opening black boxes is made 
feasible by 'moving in time and space until one finds the controversial topic on which [actors] are busy at work' (Latour 1987: 4). Arguably then, understanding why heat has become immutable in the home can be revealed through considering how individual components are negotiated into position during installation.

The installation scene, where the heating system is undergoing change, may involve persuading different actors to play the roles proposed for them (Akrich 1992), negotiating them into position and encouraging them to mingle with existing arrangements. To study how actor-networks are stabilised, we have to 'find circumstances in which the inside and the outside of objects are not well matched. We need to find disagreement, negotiation, and the potential for breakdown' (Akrich 1992: 207). As Law notes, 'for the healthy person, most of the workings of the body are concealed, even from them' (1992: 384). It is only in these moments of change, when someone is ill, or a central heating system is replaced, that these otherwise single, coherent objects are opened up to expose the complex networks of vital organs, arteries, and pumps that comprise them. During installation, the system, and the individual components that constitute this, vie for position alongside the existing socio-technical arrangements of the property, and within installers' work. In order to understand how the central heating system and its use come to be, it is valuable to look at the installation process.

\section{Data collection}

An ethnographic approach affords the perfect opportunity to 'follow the actors' whilst negotiated installation takes place. This can help to avoid pre-defined categories and conceptions of how different components interact before witnessing it first-hand (Latour 2005: 12). In order to gain an understanding of "what technologies mean to actors, and how they are actually used in everyday life' (Lutzenhiser 1992: 55), it is imperative that such studies of the technical are positioned in the sites and relations of their everyday use (Suchman et al. 1999: 397).

Early applications of this approach in STS started in scientific environments and laboratories (Latour and Woolgar 1979), but the use of ethnography in contexts more germane to this study have yielded valuable insights. Pink et al. (2010) have highlighted the value of ethnography for understanding the 'workplace realities' of construction sites, and the role of anthropological approaches for identifying the complex contributions of workers, including tradespeople, has also been recognised (Henning 2005: 8). Killip has noted the difficulty of studying those working in the construction sector using qualitative methods because potential informants 'lack the time to participate' (2011: 188). Heating installers primarily work individually in a closed setting - the private home, meaning that observation opportunities were not in a single location, or readily accessible. In addition, the heating industry is reluctant to welcome outsiders, compounded by their awareness of regulatory compliance, monitoring, and inspection (Wade et al. 2016a). Pilot studies were used to test the feasibility of applying an ethnographic approach to the investigation of central heating installation. This included spending time onsite with two heating engineers and attending two training sessions delivered by a heating controls manufacturer. Challenges in securing fieldwork opportunities led to a refinement of the approach to focus on particular stages of the work (especially when decisions were being made, for example, during surveys), and moments when installers had the opportunity to talk through their work (such as commissioning), or in more social settings, such as training sessions.

Fieldwork opportunities could only be secured through building trust with gatekeepers in the heating industry (for example, manufacturers)and heating installers themselves. A range of data collection strategies were developed in accordance with installers' working patterns and engagement with the heating industry, more broadly. Fieldwork thus incorporated shadowing heating installers as they fitted systems in homes, and observing them in more social settings including training sessions hosted by boiler and controls manufacturers, plumbers' merchants where installers sourced their parts, and relevant trade exhibitions. In keeping with the ANT approach used, observation and interviews sought the perspectives of heating installers but also paid attention to the non-human elements of installation, including the physical technologies and domestic infrastructures, and also the wider network of policy and industry guidance that installers referred to. Key informants were identified through these different activities and would recommend additional research participants. This strategy resulted in a varied sample which included self-employed installers working primarily in private 
homes, along with staff from several medium-sized and one large organisation, managing installation and maintenance work with Registered Social Landlords (RSLs). The participants were all male and aged between 25 and 65 years old. They had a mix of backgrounds and routes into the industry but most of the participants had been working as heating installers for over 10 years. Whilst not statistically representative of the approximate 135,000 heating installers operating in the UK, this sample does reflect the diversity of this group. The qualified workforce consists of $73 \%$ sole traders, $19 \%$ small businesses, and only $8 \%$ large businesses (GSR 2011: 22).

Observations ranged from a few hours to a few days of shadowing the installer in a property, depending on their preferences and the work that was taking place. Some observations took place with surveyors, who visited several properties in a single day and determined the systems that would subsequently be installed. Discussion and observation would thus take place in properties, centred around the systems themselves, and also in installers' vehicles, or over the counter of a plumbers' merchant. The shadowing was conducted overtly, and resulted in observation with a variety of companies and in a range of property and tenure types. The majority of the fieldwork took place in the Greater London area, but some training sessions and interviews included installers working in Somerset and the Midlands. Greater London was chosen as the primary fieldwork location because of researcher proximity; the nature of heating installers' work meant that observation opportunities often emerged or got cancelled at short notice. Researcher proximity meant that these changes could be accommodated. Supplementary locations were determined based on where training sessions were taking place and the researcher being granted access to these by industry gatekeepers.

In addition, twenty in-depth interviews were also conducted with different heating installers, and industry actors including plumbers' merchants, and representatives of manufacturers and the heating industry's trade bodies. These were secured through the same routes as the observation opportunities. At interview, installers were asked to explain their process of determining, installing, and commissioning a heating system, along with information about their route into the industry and professional qualifications (see Appendix for an example interview schedule). The interviews were conducted in a location of the installer's choosing; they were between $45 \mathrm{~min}$ and $3 \mathrm{~h}$ in length and were audio recorded and transcribed verbatim. The varying length of interview is reflective of the participants' preferences and availability; this is common for semi-structured interviews which should follow the flow of conversation and allow for elaboration from the participant. The data was collected between September 2012 and December 2013; although now several years old, this is the only study to have collected in-depth data on the work of heating installers, including observation, in this time frame. Such actors are responsible for ensuring that installed gas heating systems work efficiently, and the potential installation of low carbon technologies. Understanding their work through insights like those collected here is thus crucial for supporting the transition to lower carbon homes.

Collectively, the study therefore involved approximately $400 \mathrm{~h}$ spent with over 100 heating installers in a variety of settings. This includes those with whom interviews and observation were carried out, and also accounts for the more informal discussions that took place, for example at training sessions and over the counter of plumbers' merchants. The data collected includes detailed fieldnotes, photographs, and interview transcripts. The data was analysed using qualitative analysis software (MaxQDA) and coded through an iterative process; this is common within the ethnographic approach for the production of descriptions and explanations as research outputs (Hammersley and Atkinson 2007). This included repeated and detailed readings of the data, and the identification of emergent themes according to recurrent ideas and events, including 'installer decision making' and 'the physicality of the heating system' amongst others. In the following section, the process of different system components establishing their position and coming together to form an operational central heating system is explored. The cases presented have been selected to demonstrate recurring themes and ideas that were both identified in the broader sample and relevant to ideas of translation and interessement from ANT.

\section{Results}

Managing the preferences of new technologies

Choosing and installing a central heating system is a fragile negotiation between accommodating its complex 
connectivity and the requirements of its different components. This analysis begins by scrutinising the preferences and requirements of some of these new system components as they take their position in the home.

Manufacturer installation guidelines state that a boiler must be positioned so that the flue carrying waste gases can be extended outside the building, and the acidic condensate can be safely drained away. According to this, for a boiler to operate successfully, it is reliant on the connectivity between a huge number of heterogeneous actors, chemical, electrical, and mechanical. In opening this white box, we see that the operation of the boiler, and its constituent parts, play a significant role in shaping the installation process:

'Well, it can be, it's silly, when you're selectin[g] a boiler sometimes it comes to do with nothing to do with the property, to do with the physical size of the appliance, one of the models you can pipe up the boiler from behind the boiler, so sometimes that has a bearing. Flue distances will have a bearing, erm, if you've got excessive flue runs to the gas, gas pipe sizing is a big issue...'.

(Eric, medium-sized organisation, interview)

As Eric notes, flue runs, pipe sizing, and gas volumes all have to be accommodated when determining which products to install. Thus, the boiler is defined through its interaction with other system components and it is impossible to enrol this device without consideration of its associated connectivity.

In turn, the network of pipes that transfer gas, water, and waste fluids has its own requirements to be considered. Industry guidance and regulations state that the gas inlet pipe that runs between the gas meter (where gas enters the property) and the boiler must be of a sufficient diameter to ensure that the correct gas operating pressure $^{5}$ can be achieved at the boiler (HSE 2013). Newer condensing boilers often require a higher gas flow rate than older non-condensing models, and so larger diameter pipes may need to be installed.

However, existing gas pipes are often hidden underneath carpets and behind kitchen units, making it difficult for heating engineers to know their size without ' $x$ ray eyes' (Jeff, self-employed, interview). The disruption that changing a well-established gas pipe would cause can be enough to shape the choice of boiler, for

\footnotetext{
${ }^{5}$ The pressure of gas at which the boiler is designed to operate.
}

example, selecting one that requires a lower gas flow rate. Conversely, the preferences of the boiler may be disregarded in favour of an existing gas pipe. For example, I observed Roger deciding not to disturb the original gas pipe during a boiler replacement; he elaborated on his decision, explaining that

they had piped the boiler up to a $15 \mathrm{~mm}$ gas pipe, when really it should be a $22 \mathrm{~mm}$...it was all working fine though because there was a decent amount of gas coming through the meters in these properties. He said that if there had not been enough gas, he would have increased the size of the gas pipe, but that would [have] increased the cost of the job because they would've had to run the gas pipe all the way back to the meter.

(large organisation, fieldnotes)

The cost (in terms of finance, labour, and disruption to the property) of installing a new gas pipe from the meter to the boiler proved too prohibitive for Roger to replace this component. As Roger notes, this particular boiler should really be attached to a 22-mm gas pipe; this is to ensure that it has a high enough gas flow rate to achieve the required gas inlet pressure specified by the boiler manufacturer. In this case, the existing smaller gas pipe is translated into the role of providing a higher gas flow rate. During a later observation, a colleague of Roger's tested the flow rate and found that the gas inlet pressure actually failed to comply with the manufacturer's instructions. Consequently, this negotiation, in which the existing gas pipe proved to be too troublesome and expensive for the installer to move, has overridden the industry guidance provided, and potentially compromised the operation of the newly installed boiler. $^{6}$

Similarly, guidance available for the installation of heating controls does not always take priority. The minimum control requirements for a conventional heating system are a programmer with independent controls for heating and hot water, a room thermostat, and thermostatic radiator valves (TRVs) on all radiators except in rooms with a room thermostat (DCLG 2013). In their article exploring the reliance of domestic technologies

\footnotetext{
${ }^{6}$ The gas inlet pressure denotes the pressure at which gas enters the boiler. It is important that this is high enough to ensure that sufficient combustion can take place to satisfy demand when the boiler is operating at maximum output. However, the compromise detailed here is not sufficient to make the new boiler unusable or dangerous.
} 
on the temperature of the air around them, Shove, Walker, and Brown suggest that we might think of 'the ambient air as part of the device itself' (2014: 19). For example, they highlight domestic computer equipment that is designed to operate comfortably at $22{ }^{\circ} \mathrm{C}$ (Shove et al. 2014). This is especially true for thermostatic central heating controls, which 'call for heat' when they recognise that the surrounding ambient air is not at the required temperature. The ambient air is thus an actor, shaping the position and operation of these devices. This is recognised in British Standards guidance which stipulates that an air temperature sensor should be located in a position 'representative of that part of the system which it controls...it should not be exposed to draughts or cooling effects and [should be] away from any heat sources' (BSi 2013: 46). However, this important interaction between control devices and ambient air does not always take priority in the installation process.

In one case, I joined Gary as he was wiring in the controls for a recently installed replacement boiler. For this, he adopted a 'like-for-like' strategy, installing the new room thermostat in the footprint of the old one (see Fig. 1-where the barely disrupted paintwork can be seen down the right hand side of the new thermostat).

Gary commented that 'the thermostat wasn't really in the best place; that it should be on the wall behind, because at the moment it was attached to an external wall right next to the door...' (mediumsized organisation, fieldnotes). With this positioning, the thermostat would be subject to colder temperatures. This could potentially cause disruption to the operation of the heating system, for example calling for heat when the remainder of the house is already at the desired temperature. In this translation, the installer recognised that this was not 'the best place', but overruled the thermostat's preferences in order to minimise disruption to the existing socio-technical scene. New components thus have clear preferences for where they are located and how they are interconnected. These preferences can be inscribed into associated guidance and instructions. However, these devices are also vying for position within a property's established sociotechnical networks and their preferences may not always take priority. Where existing arrangements demonstrate a high level of reluctance, these preferences can be undermined, as explored in the following section.

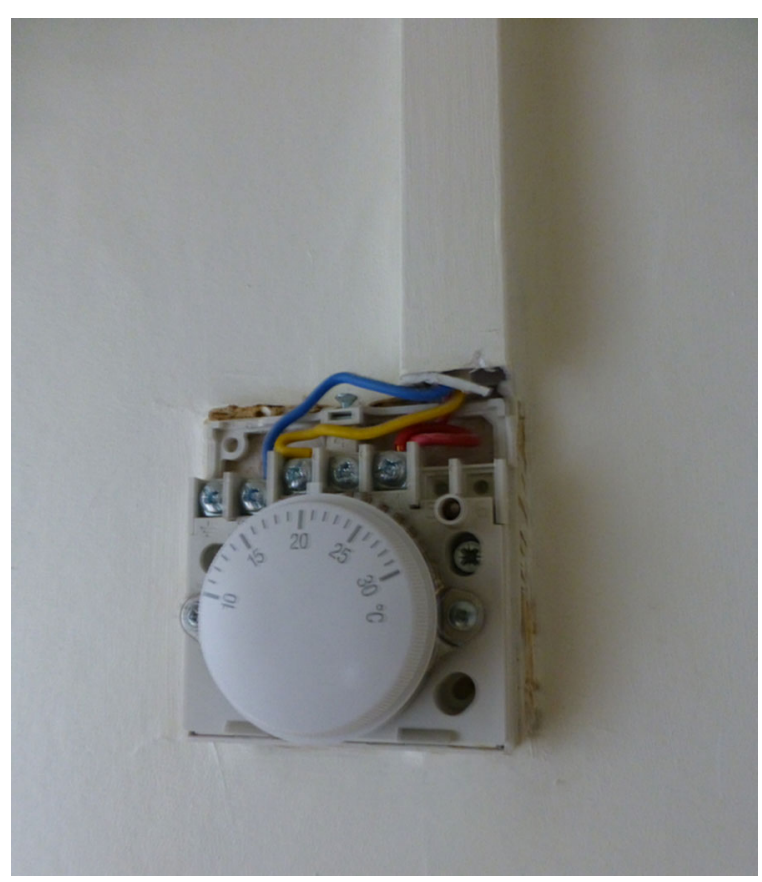

Fig. 1 A new well-established room thermostat

Adapting to the recalcitrance of existing arrangements

Industry guidance suggests that boilers must be sited in a position that is 'readily accessible for operation, inspection, and maintenance' (HSE 1998: 15). Requirements to connect to drainage and gas networks can mean that these devices are often located in kitchens. Existing furniture, cupboards, and appliances, along with the occupant's and installer's preferences, can all contribute to contested boiler positioning:

[Eric] also looked at the positioning of the boiler, which had a kitchen cupboard in front of it. $\mathrm{He}$ assessed the size of the space and said that he would have to go with an Ocipura for servicing purposes, because with the Bedlington Boilers you have to take the whole front cover off including the side panels and there would not be space to remove that because of the cupboard, whereas with the Ocipura you just have the front panel to remove.

(medium-sized organisation, fieldnotes)

The front cover of the Ocipura boiler that Eric describes is much shallower than the alternative Bedlington, meaning that less space is required in front of the boiler to remove it. However, to access the boiler 
controls (the customer's point of interaction with this technology), the Ocipura case includes a fold down cover that, once the boiler was installed, could not be opened because of an encroaching kitchen cupboard (see Fig. 2). This translation has prioritised the system builder's access to the boiler's inner workings over the occupant's access to the boiler controls. Arguably, this may have a detrimental impact on the occupant's ability to interact with the technology and contribute to its position as a device that sits in the background.

This tussling with the property's existing sociotechnical arrangements is also true as pipework takes its place in the home. In a one-bedroom flat, two installers, Shaun and Hasan, were discussing how to connect the gas meter at one side of the room to the new boiler at the other:

Hasan was looking at the route between the gas meter and the cooker, he indicated below the cupboards and said that the gas pipe could go along here and connect up behind the cooker. At this point Shaun pulled the cooker out to have a look behind it. He said yeah, the gas goes behind

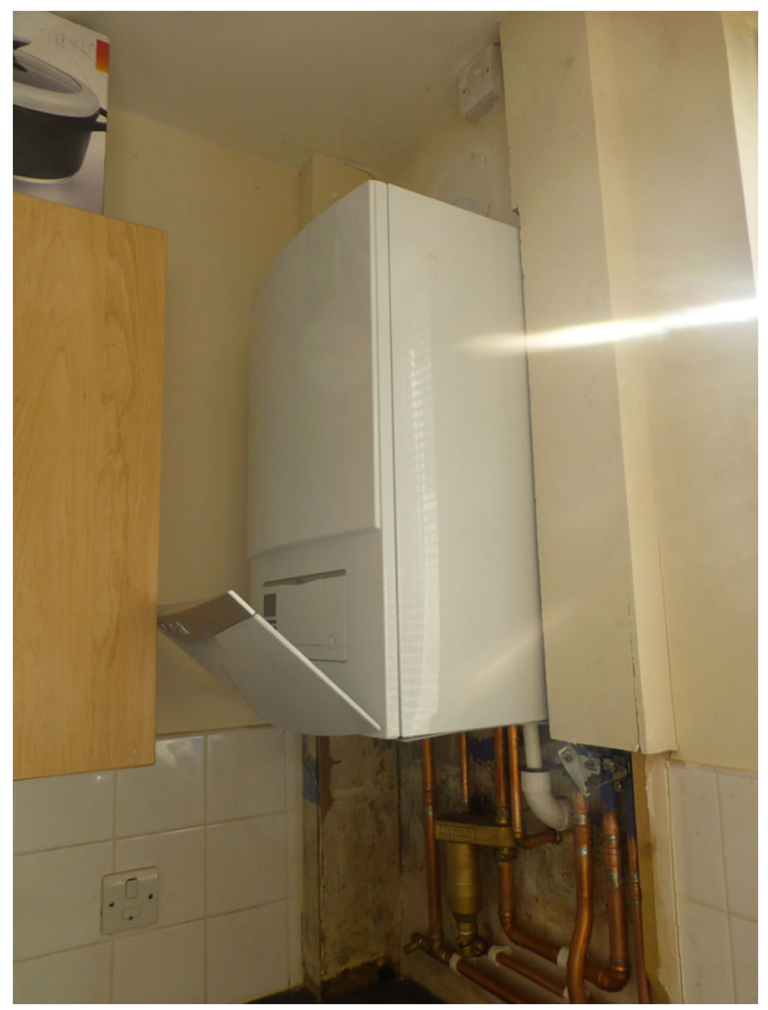

Fig. 2 A user friendly installation there, but how would they get round the side of the cooker - the pipework would not fit down the side.

(medium-sized organisation, fieldnotes)

In this proposed interessement, the cooker is identified as a potential collaborator; the gas pipe could be connected to the existing pipework behind it. However, during the installation, the cooker would not yield enough space to accommodate the gas pipe. Instead, the space within the kitchen cupboards and above the door provided a suitable home for the new pipework (see Fig. 3).

There was a compromise in this case; some elements of the existing kitchen arrangement were resolute in their position, in particular, the cooker. This translation resulted in the new actor, the gas pipe, being left uncomfortably exposed around the top of the kitchen. The installers agreed that the compromise 'wasn't too bad, especially because it was above eye level and you didn't really look up there'.

Compromise between existing networks of pipes and furniture can also dramatically shape the sizing of radiators. During one survey, Eric hesitated as he was measuring an existing bathroom radiator in order to determine its replacement:

He explained that size is the limiting factor and that the manufacturers have changed over the years and they have set sized radiators - he pointed out that the flow and return pipes for the radiator had been boxed in as well - so it would be difficult to alter those.

(medium -sized organisation, fieldnotes)

In this property, the flow and return pipes connecting to the radiator had been enclosed in boxes, making the existing pipework unwavering in its position. Rather than disrupt this scene, this translation resulted in a radiator with dimensions that would fit into the existing arrangement. However, this size-for-size replacement may not be optimum for energy-efficient operation of the system, or thermal comfort, and is contrary to recommended industry sizing procedures (HSE 1998; EST 2008). In another case, a tenant explicitly requested that an existing single panel radiator in the living room was exchanged for a double panel device. The installer, Eric, suggested a single panel would be more suited to the space. However, the tenant's request combined with the 

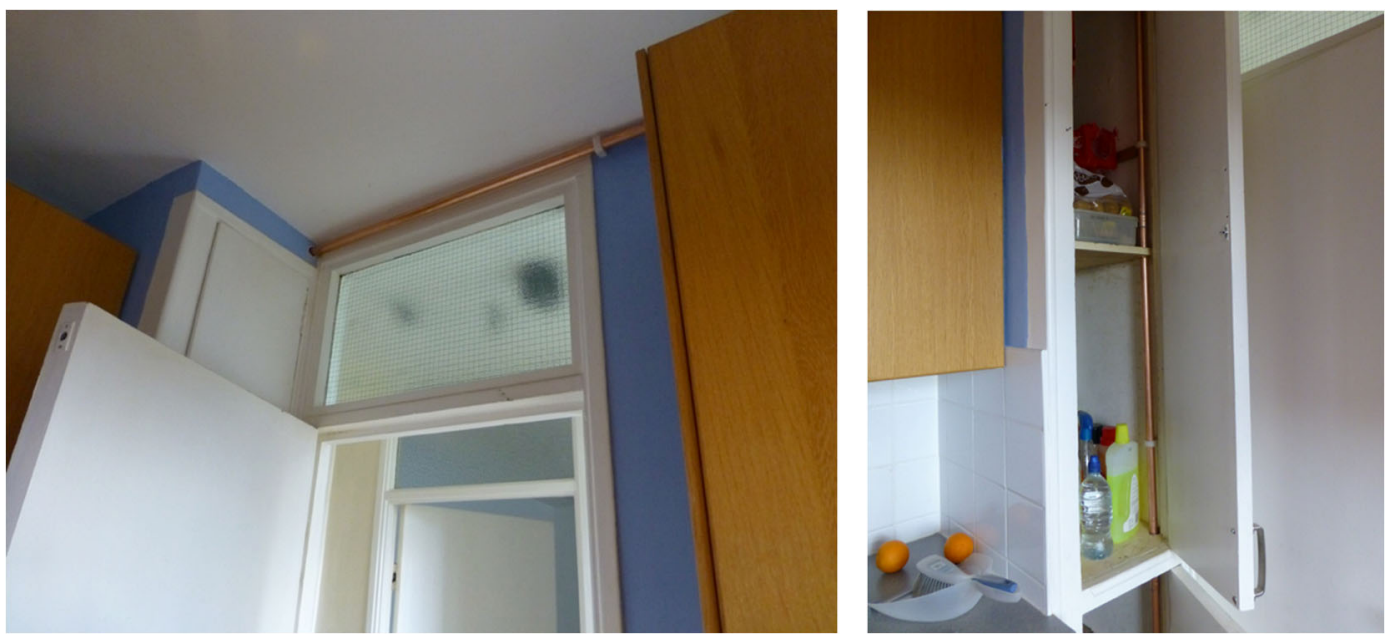

Fig. 3 Uncomfortable pipework

disruption that a single panel radiator (of slightly different dimensions) would cause to the existing laminate flooring resulted in him specifying the double panel device. This contestation between what will physically fit into available spaces, minimise disruption to existing arrangements, and achieve an appropriate heat output often leads to simple replication. However, in this case, since the installation of the original heating system, the property had additional external wall insulation fitted. This would have increased the property's ability to retain heat, making the additional large radiator even more unnecessary.

Thus, existing kitchen units, furniture, and pipework can all be so reluctant to change that, in translation, new central heating components have to squeeze into existing spaces, take on the shape and size of old system



Fig. 4 Radiators 'locked in' by boxed away pipes parts, and form alliances that may not create the most energy-efficient system configuration.

\section{Hiding heat}

Ensuring that new boilers and their associated components do not disrupt existing socio-technical arrangements can dominate the negotiations taking place during installation. Despite its importance as the heart of the central heating system, the visible presence of the boiler is not necessarily desired. In keeping with this, the aesthetic and spatial implications of different types of central heating system may shape product decisions. For example, Carl highlighted his customers' preference for combination boilers, which do not require a separate water tank and consequently take up less space than the alternative system boiler. Unlike the coal fire, which was once a focal point for the family, the boiler is not an attractive item to have on display. As Gary explained:

'You don't [h]ave a cocktail party and bring your mates down to the basement and say 'look at my boiler', but whereas your, your three quarter of a million-pound kitchen that everyone's standin[g] in with your fancy oven and what not, people see that don't they?'

(Gary, sales representative, interview)

During observation, it became apparent that this problem could be overcome by hiding the boiler, encouraging it into small spaces, or encasing it in a cupboard. 
Pipework experienced a comparable need to overcome its undesirability in order to take its position in the home. Keith noted 'no-one wants pipework running everywhere in their [house]' (medium-sized organisation, interview), whilst Roy highlighted 'no-one wants pipes traipsing from $\mathrm{A}$ to $\mathrm{B}$, clothes lined along a wall' (self-employed, interview). In response to this, efforts may be made to minimise the length of pipe in the property. When hot water is demanded, there is a delay whilst it is heated and travels along the network of pipes to the location where it is needed. During this time, cold water comes out of the tap, which can be wasteful. The length of redundant pipework is known as the dead leg, and it is important for the system builders to minimise this lifeless limb. In one case, Eric and his colleague Adrian decided that a new boiler would be best located in a bedroom adjacent to the bathroom. With the boiler so close to the bathroom, there would not be 'pipes flying in any direction', ensuring that the system was 'less offensive to the eye' (medium-sized organisation, fieldnotes). Alternatively, the interessement of new pipework to make it hidden might be achieved by 'boxing in', disguising it by painting it white or positioning it in spaces less visible, for example the loft (Fig. 5).

Similarly, heating controls are expected to match the footprints of their predecessors, blend in with existing socio-technical arrangements, and hidden from view. During observation, a heating engineer consulted the tenant ahead of positioning the new programmer:

he asked the householder whether they wanted the controls "hiding", and asked them to come upstairs so he could show them. He positioned the programmer underneath the boiler, on the left hand side - it was very close to the boiler and pipework. There was also a large wardrobe to the left of it. The customer said that the programmer would be great in that position, and that it would be good hidden.

(medium-sized organisation, fieldnotes)

This black boxing through hiding (illustrated in Fig. 5) may have a detrimental impact on the use and usability of heating controls: if people cannot find or identify their controls, logically, they may struggle to use them (Lutzenhiser 1992; Rathouse and Young 2004; Meier et al. 2011). This is something to be wary of in the development and wide-scale distribution of advanced

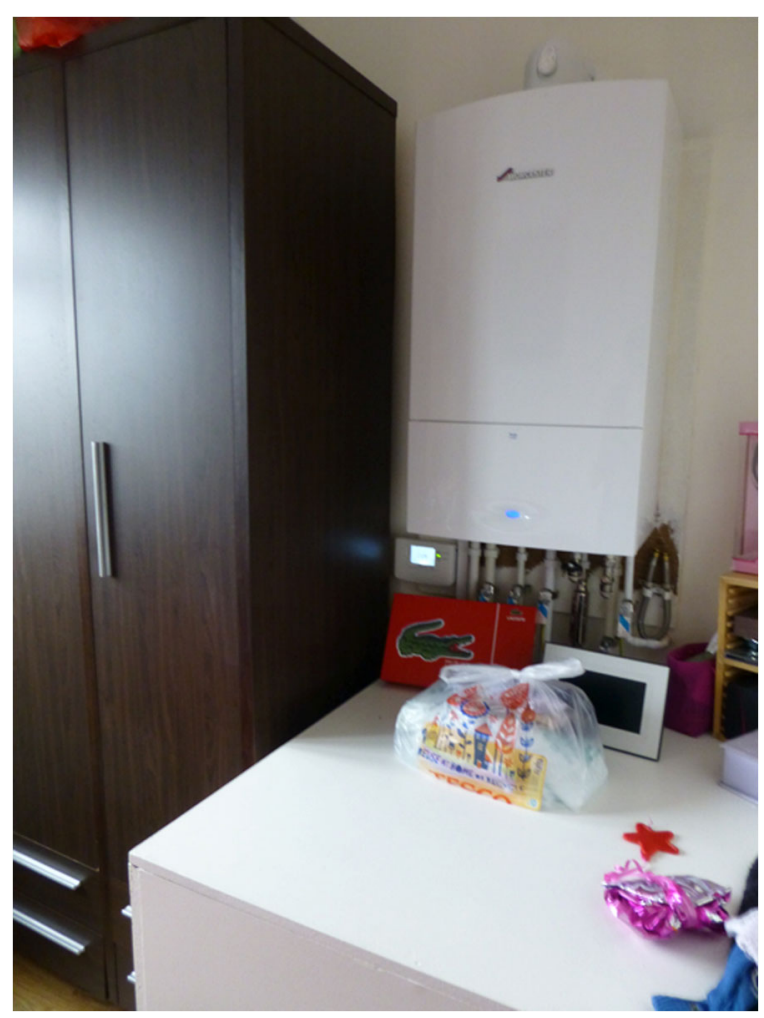

Fig. 5 'Hidden' controls

('smart') heating controls. These still rely on interaction from the end-user (whether via a smart phone or the device itself) and are unlikely to achieve their promise of improved usability if attempts are made to hide them from the minds or everyday lives of occupants. Indeed, these uncomfortable new alignments and collaborations are not always in keeping with the preferences of the controls themselves. In one property, Roger, the installing engineer, highlighted to the customer that he had fitted a new TRV on the radiator (Fig. 6).

He pointed out to the customer that he did not want his TRV 'cuddled' with the curtains, he demonstrated by moving the curtain away from the TRV - he said that it would think it was warmer than it actually is if the curtain is 'cuddling' it.

(large organisation, fieldnotes)

Roger warned against these two actors getting too close, since the curtain might deceive the TRV into thinking that it is hotter than it actually is, potentially disrupting its ability to manage the operation of that 


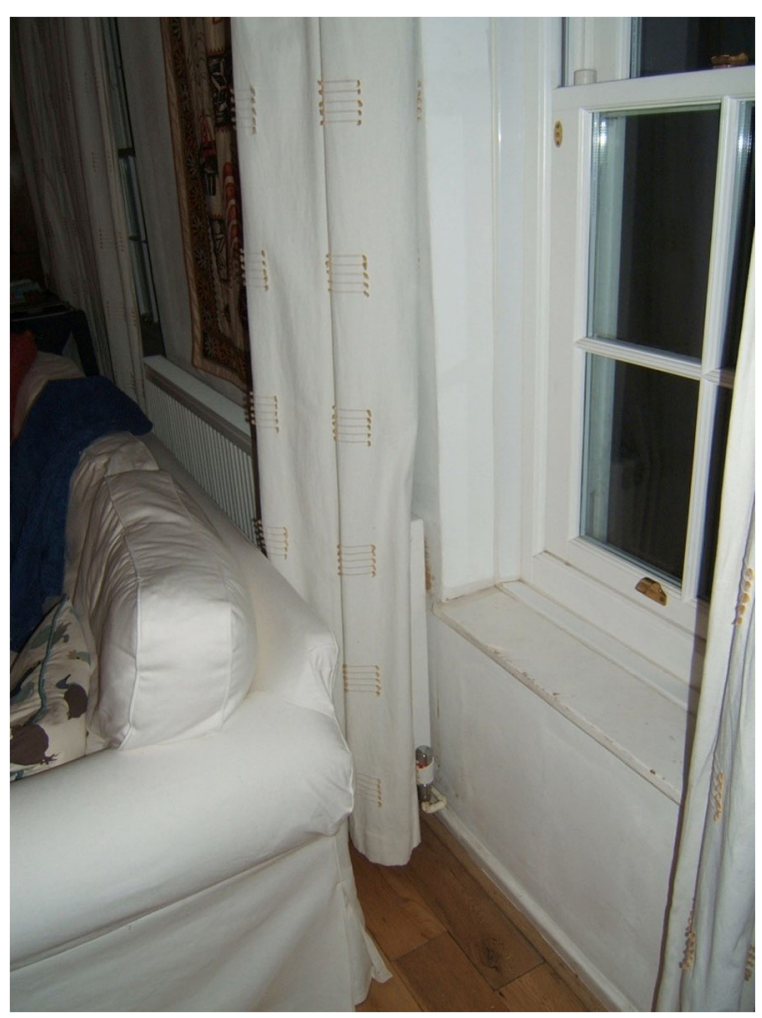

Fig. 6 Too close for comfort

particular radiator. This translation of the radiator and the TRV with the sofa and heavy curtain are also contrary to guidance to keep these devices clear of obstruction (EST 2008; BSi 2013) and could limit the user's potential interaction with it. However, the controls can fight back, using bright lights and backlit screens to increase their visibility. During one manufacturer training session, the course instructor noted that a particular control device has 'got a very very bright screen', along with LEDs that are a 'very very bright green colour' to ensure that it can be seen, which, he suggested, is ideal for when the device is installed in a cupboard (manufacturer training, audio). Installers may consequently perceive these active devices as functional regardless of their location, meaning that interessement may include identifying how these devices can be hidden or positioned in locations less convenient.

\section{Discussion}

The urgency of reducing the energy consumed through domestic space heating, and implementing alternative low-carbon heating technologies, is escalating. To meet the UK Government's 'net zero' 2050 target (HM Government 2019a), it is increasingly critical to understand the perspectives of the variety of actors involved in shaping how heating technologies take their place in the home. In this paper, heating installers have been positioned as middle actors (Parag and Janda 2014), responsible for orchestrating the translation and interessement of different components as gas central heating systems are upgraded, or newly positioned in homes.

Attempts are made to ensure that the heating system disrupts existing socio-technical arrangements as little as possible; this system may be expected to blend in with its surroundings, squeezed into kitchen cupboards, or boxed away. Examples discussed here, including the installation of like-for-like technologies and concealment of system components, indicate efforts to limit opportunities for adaptation. This enduring use of certain control technologies is likely to contribute to the limited strategies identified for central heating temperature and timing settings (Huebner et al. 2014; Hanmer et al. 2019). In particular, the data presented adds to existing evidence that heating controls are placed in inaccessible positions, and in the footprint of existing devices (Rathouse and Young 2004; Meier et al. 2011). Smarter heating controls are heralded for their ability to deliver more energy-efficient management of heating systems. This will not be the case if, in their translation and interessement, the advanced interfaces of these devices are concealed from view or their occupancy detecting sensors are hidden in cupboards.

There is work carried out during installation to retain the now stabilised and accepted configuration of central heating systems. This highlights just how deeply embedded socio-technical arrangements around heat and thermal comfort are (Shove 2003). Installer efforts to 'keep this black box closed' (Jacobs et al. 2007) may be a hindrance to change. Normalisation makes links predictable and reduces the number of translations required to take place for the alignment of different actors (Callon 1991). Arguably, the selection of a boiler to fit in the available space and with existing pipework may be the result of a normalised installation process. In a significant removal from recommended sizing procedures, and to maintain established and predictable connectivity, the output of radiators might be determined based on what will fit in the available space or on a simple 'like-forlike' basis. Heating engineers are clearly playing a middle actor role here; their downstream influence to 
customers is apparent through their selection of technologies that are most convenient (Parag and Janda 2014; Janda et al. 2014). Despite what industry guidance might recommend, with their mediating role, installers and existing technologies can push new devices to fit into existing moulds. This ambivalence towards regulations is problematic for policy strategies that rely on recommendations made via Building Regulations, but could act to reinforce installers' agency within this network (Singleton and Michael 1993). During a normalised installation, the smooth alignment of new actors with old networks takes precedent over optimising the energy efficiency of the new system in operation. With such effort being expended on ensuring equivalence, rather than central heating installation being a potential moment to introduce new technologies, it is instead a moment for reproducing and reinforcing existing sociotechnical arrangements and associated space heating practices.

To undo existing translations is expensive; established links between actors need to be reversed, new actors need to be introduced, and new alliances formed (Callon 1991). Although heating installers hold a high degree of agency in the decisions made around the installation of gas boilers, this paper has shown that their role as middle actors is a negotiated performance. This is significant for the suggestion that gas boilers will be banned in new homes in the UK from 2025 (Government 2019b), with efforts to fit alternative low carbon heating systems. Nyborg and Røpke (2015) suggest that a large number of interessement devices have already been developed for the dissemination of heat pumps, such as policy papers. In this way, the broader actor-network is beginning to coalesce around lowcarbon technologies. However, this analysis reveals that a vast array of additional translation work needs to take place in the home and during the installation process in order for such new technologies to stand a chance of becoming established. Without this, there will be a continuation of new technologies being assimilated into existing socio-technical contexts, rather than being used in the way intended and achieving potential energy efficiency gains (Judson et al. 2015). In addition, the role of heating installers may be compromised with the loss of familiar gas boilers or the introduction of alternative technologies. For example, heat pumps will require engagement from those with electrical expertise, whilst district heating systems require public and private sector interests to coalesce. This consideration of the changing configuration of middle actors (Janda and Parag 2013; Parag and Janda 2014) for heating installation will be crucial for harnessing the expertise of this workforce and supporting their engagement in this future transition. Extending the current ANT analysis to consider alternative technologies can usefully tell us about the 'inclusive participation' of existing sociotechnical arrangements and sensitivity to the context in which they are to be implemented (Chilvers et al. 2018). This can provide a better understanding of the implications of new technologies for existing actor configurations, and which new actors will need to be recruited.

This detailed look at installation as relevant actors are mobilised and translated into position has highlighted the value of ANT for emphasising the materiality of central heating installation.

Translation can include identifying suitable components to ensure the smooth operation of a boiler or assuming that existing parts (for example, and undersized gas inlet pipe) will function sufficiently. The concept of translation offers a useful way to identify how the interests of different actors are enrolled to function together (Callon 1991). Meanwhile, interessement has been used to explore how allegiances form between different actors in the central heating network (Akrich et al. 2002). This is helpful for identifying how actors may resist engaging (for example, existing pipework and kitchen cupboards) and also the ways in which these preferences may be overcome as the negotiated system takes shape. These concepts are thus valuable for providing an understanding of how established ideas of gas central heating networks are replicated through new installations and replacements. However, the notions of translation and interessement do not provide a toolkit for how new technologies may come to take their position in the network. For example, they do not reveal how established ideas of actor roles (such as controllers that should be hidden) can be overcome.

In addition, heating installers are not able to fully control the installation scene. As Yaneva (2008: 23) notes in her study of building renovation, the building is a performative agent that 'cannot be entirely mastered by [human actors]...[it] resists with stubbornness, hinders or facilitates specific ways of accommodating... requirements'. In this case, the heating installer is not necessarily afforded the liberty to 'suggest more or less what he sees fit' (Banks 2000a: 8.10); instead, their work is determined through negotiation between a number of heterogeneous actors. Heating installers' 
participation in the negotiations taking place during installation is shaped by information learnt through guidelines and regulation and also by their own experiential knowledge (see Wade et al. 2016a). In heating installers' orchestration of the installation process, this paper has shown that these middle actors are far from 'peripheral' humans (Callon 1991). In applying their own understandings to central heating installation, installers clearly have agency within their socio-technical networks. Such intentionality and motives distinguish heating installers from other installation actors, making the aspirational symmetry of ANT flawed (Pickering 1993). The failure of ANT to incorporate the skills and tacit knowledge that exist amongst human actors has been highlighted (Collins and Yearley 1992). Pickering suggests that to break this symmetry, there is a need to incorporate human intentions, goals, and purposes (1993).

This asymmetrical agency within the actor-network of heating installation is also apparent through consideration of the end user. Building occupants were usually not present for the installation and did not always play a significant role in the negotiations taking place in their home. Star (1991) highlights that science and technology studies are guilty of privileging particular points of view, especially of those with more power. The perspectives afforded through this fieldwork were through discussion and observation of the installation process with heating installers. This is characteristic of the ANT approach that 'finds heroes to be more interesting than ordinary folk' (Law 1991: 13). However, this is problematic in that it can result in the neglect of actors that are already systematically excluded from these processes (Murdoch 1997), and it creates a biased perspective of the installation process. Further research should look to bridge these perspectives with those collected on householders' experiences of the installation process (for example, Judson et al. 2015). In addition, a heating system can be subject to evolution in its use depending on what auxiliary services and points of interaction are added (for example the types of heating control) (Silvast et al. 2018). To capture this, the current ANT analysis would need to extend beyond installation, to observe use over a longer timeframe. This could be achieved with consideration of the 'series of configurational movements' in sites of design and use throughout a technology's lifetime. It has been suggested that a 'biographies of artifacts and practices' approach could thus usefully add to ANT through accommodating longitudinal and multi-sited strategies (Hyysalo et al. 2019). This could deliver greater understandings of the changing negotiations and agency within the actornetwork throughout the lifetime of an object.

\section{Conclusion}

This paper has revealed the negotiation of preferences as central heating components take their place in the home. The positioning of the different system components is a process of minimising disruption; this might include installers fitting 'like-for-like' products, ones that will blend in with existing socio-technical networks, or devices that can be hidden in the home. In this process, heating installers are subject to the priorities and preferences of the technologies being installed, existing sociotechnical arrangements, and conduct their own performance as experts. The regulations and sizing procedures stipulated in industry guidance are not always prioritised, meaning that the energy efficient operation of the central heating system may be compromised.

These findings indicate that any efforts to improve the standards of installed heating systems will be compromised. Government still relies on a techno-centrist approach to policy making, requiring the installation of technologies with improved technical efficiencies or alternative systems. These rarely account for in situ performance, and it is inadequate to rely on requirements set out in Building Regulations, which are far removed from the lived realities of heating upgrade and installation. Situationally specific negotiations and compromises like those detailed in this paper contribute to recognised gaps between the anticipated and realised energy performance of dwellings. In order to overcome such performance gaps, policy makers need to think in actor-network terms. This will require extending beyond stipulating standards via Building Regulations, to reviewing the uptake of new skills standards for building professionals (for example, through PAS 2035). Critically, and in keeping with the Committee on Climate Change's (2019) recommendation, this will need to be accompanied by a strengthening of compliance and enforcement frameworks.

Acknowledgements The author would like to thank the heating installers and industry representatives that made the research possible. This research stemmed from a PhD thesis, supervised by Dr. Russell Hitchings and Michelle Shipworth. The author is also grateful to Dr. Sarah Parry and Professor Janette Webb, who read 
early drafts, and three anonymous reviewers who provided constructive comments and strengthened the paper.

Funding information This research was supported by the EPSRC, under grant numbers EP/L01517X/1 and EP/H009612/1.

\section{Compliance with ethical standards}

Conflict of interest The author declares no conflict of interest.

\section{Appendix}

Installer Interview Schedule 2013.12.03

Briefing

- Why?

- Researching CH installation and use

- Understanding from an installer perspective - what the job involves

- Funded by EPSRC - university based project

- The interview

- Approx. $1 \mathrm{~h}$

- Informal conversation - question sheet as guide

- Recorded

- Confidential - securely stored

- Anonymised outputs

- Any questions?

\section{Section 1: Background}

Could you tell me about your current job?

- Working for a company/ self employed?

- If with company - what kind of company, what size?

- Specializing in particular role (surveyor/ engineer/ breakdowns)?

- How long in the job?

\section{Section 2: The Installation process}

Could you talk me through the process of a central heating installation, so from the first point of contact with a customer to the point where they have a new, working central heating system? [Does not have to be full system - can be just boiler/ controls]

\section{Survey/ Quotation}

Can you explain to me how each part of the system is chosen?

- Boiler, radiators, controls

- Preferred suppliers / manufacturers - reasons? Always same?

- Makes, models, location

- Involvement of customer? Products specified by contract?

- Sizing - calculations, tools [Are customer routines relevant to this?]

\section{Physical install}

What sort of issues might you get during the physical installation? How are these resolved? Need to talk to customer?

Commissioning

Can you talk me through the commissioning process?

- Filling in documents - what documents? Who receives copies? What do you think to these? Commissioning Checklist required?

- Documents signed by customers - do you explain the documents/ do they ask questions about the documents before signing? Is it important that the customer signs?

- What is tested?

- Any problems/ difficulties during commissioning?

- What do you think to this process? Sufficient to make sure the systems are fitted correctly? 


\section{Section 3: Handover/ Customers}

Do you show customers their new system?

- Set up programmers for them? Ask customers about their routines?

- Leave instructions?

Do you get customers who struggle to use their system? Do you get call backs from people?

How do you avoid or deal with call backs?

- Explain?

- Install certain types of controls?

How are customers with you? Interested in the system? Not bothered? Away from the house?

Are some customers easier to deal with than others? Which ones are easy/ difficult?

What do you think is the most efficient way to use a central heating system?

\section{Section 4: Maintaining expertise}

Why did you decide to become a central heating installer?

Could you talk me through what training you went through to become a central heating installer?

- What training routes? [college, NVQ, training through company?]

- What qualifications?

$$
\text { NVQ's/ GasSafe/H\&S }
$$

Is there a lot of change in the field?

- What sorts of changes? [Different qualifications? Regulations?]

- $\quad$ New controls - smart controls in homes, how do you feel about installing those?]

If so, could you tell me how you keep up to date with these changes?

- Training courses/ GasSafe renewal

- Sources of information?
- Particular contacts?

- Documents? Publications?

- Professional bodies?

\section{If recruited at manufacturer training course:}

- How did you find out about it?

- Why did you attend?

- Continuing contact - other installers? Trainers/ manufacturers?

Open Access This article is licensed under a Creative Commons Attribution 4.0 International License, which permits use, sharing, adaptation, distribution and reproduction in any medium or format, as long as you give appropriate credit to the original author(s) and the source, provide a link to the Creative Commons licence, and indicate if changes were made. The images or other third party material in this article are included in the article's Creative Commons licence, unless indicated otherwise in a credit line to the material. If material is not included in the article's Creative Commons licence and your intended use is not permitted by statutory regulation or exceeds the permitted use, you will need to obtain permission directly from the copyright holder. To view a copy of this licence, visit http://creativecommons.org/licenses/by/4.0/.

\section{References}

Akrich, M. (1992). The de-scription of technical objects. In W. Bijker \& J. Law (Eds.), Shaping technology/ building society: studies in sociotechnical change (pp. 205-224). Cambridge: Massachusetts Institute of Technology.

Akrich, M., Callon, M., \& Latour, B. (2002). The key to success in innovation part I: the art of interessement. International Journal of Innovation Management, 6(2), 187-206.

Arapostathis, S., Carlsson-Hyslop, A., Pearson, P. J. G., Thornton, J., Gradillas, M., Laczay, S., \& Wallis, S. (2013). Governing transitions cases and insights from two periods in the history of the UK gas industry. Energy Policy, 52(C), 25-44.

Banks, N. (2000a). Socio-technical networks and the sad case of the condensing boiler. In ACEEE 2000 Summer Study. Pacific Grove, California, pp. 8:1-8:12.

Banks, N. (2000b). Appendix C: The UK domestic heating industry - actors, Networks and Theories, Lower Carbon Futures.

BEPA. (2014). Building energy performance assessment - support website: Database listing application for boilers \& microCHP. Building Energy Performance Support Website. Available at: https://www.ncm-pcdb.org.uk/sap/page. jsp?id=48 [Accessed 23 December 2019].

Bowden, F., Brass, C., Watson, B., Mitrovic, D., Tompkins, J., Zygmunt, J., \& Jordan, D. (2012). Plug-it: final report to the Department for Environment Food and Rural Affairs. London: SEED Foundation, Policy Studies Institute and Waterwise, Defra. 
BSi. (2013). BS EN 14336:2004 Heating systems in buildings installation and commissioning of water based heating systems, British Standards Institute.

BSi. (2019). PAS 2035/2030: 2019 Retrofitting dwellings for improved energy efficiency - specification and guidance, British Standards Institute; Department for Business, Energy \& Industrial Strategy.

Collins, H. M., \& Yearley, S. (1992). Journey into Space. In A. Pickering (Ed.), Science as Practice and Culture (pp. 369389). Chicago: University of Chicago Press.

Callon, M. (1986a). Some elements of a sociology of translation: domestication of the scallops and the fishermen of St Crieuc Bay. In J. Law (Ed.), Power, action and belief: a new sociology of knowledge? (pp. 196-223). London: Routledge.

Callon, M. (1986b). The sociology of an actor-network: The case of the electric vehicle. In M. Callon, J. Law, \& A. Rip (Eds.), Mapping the dynamics of science and technology: sociology of science in the real world. London: The Macmillan Press Ltd..

Callon, M. (1991). Techno-economic networks and irreversibility. In J. Law (Ed.), A sociology of monsters: essays on power, technology and domination (pp. 132-161). London: Routledge.

Callon, M., \& Law, J. (1997). After the individual in society: lessons on collectivity from science, technology and society. The Canadian Journal of Sociology, 22(2), 165-182.

CCC. (2019). UK housing: fit for the future? Committee on Climate Change.

Chilvers, J., Pallett, H., \& Hargreaves, T. (2018). Ecologies of participation in socio-technical change: the case of energy system transitions. Energy Research \& Social Science, 42, 199-210.

CIBSE. (2013). Domestic heating design guide. The Chartered Institute of Building Services Engineers.

Clendinning, A. (2000). Deft fingers' and 'persuasive eloquence': the "lady demons" of the English gas industry, 1888-1918. Women's History Review, 9(3), 501-537.

DBEIS. (2019). Energy consumption in the UK (ECUK) 1970 to 2018. Department for Business, Energy and Industrial Strategy.

DCLG (2013) Domestic building services compliance guide, Department for Communities and Local Government.

de Laet, M., \& Mol, A. (2000). The Zimbabwe bush pump: mechanics of a fluid technology. Social Studies of Science, $30(2), 225-263$.

EST. (2008). CE30 domestic heating by gas: boiler systems guidance for installers and specifiers. Energy Saving: Trust.

Government, H.M. (2008) Climate Change Act 2008

Government HM. (2010). The Building Regulations 2010.

Government HM. (2017). Heat in buildings - boiler plus Department for Business, Energy \& Industrial Strategy.

Government HM. (2018). The clean growth strategy - leading the way to a low carbon future.

Government HM. (2019a). The Climate Change Act 2008 (2050 Target Amendment) Order 2019. Available at: https://www. legislation.gov.uk/ukdsi/2019/9780111187654 [Accessed 23 December 2019].

Government HM. (2019b). The future homes standard: 2019 consultation on changes to part L (conservation of fuel and power) and part $\mathrm{F}$ (ventilation) of the building regulations for new dwellings. Ministry of Housing, Communities \& Local Government.

Gram-Hanssen, K. (2010a). Residential heat comfort practices: understanding users. Building Research \& Information, 38(2), 175-186.

Gram-Hanssen, K. (2010b). Standby consumption in households analysed with a practice theory approach. Journal of Industrial Ecology, 14, 150-165.

GSR. (2011). Gas competence review. Gas Safe Register.

Hammersley, M., \& Atkinson, P. (2007). Ethnography: Principles in practice (3rd ed.). London: Routledge.

Hanmer, C., \& Abram, S. (2017). Actors, networks, and translation hubs_gas central heating as a rapid socio-technical transition in the United Kingdom. Energy Research \& Social Science, 34, 176-183.

Hanmer, C., Shipworth, M., Shipworth, D., \& Carter, E. (2019). How household thermal routines shape UK home heating demand patters. Energy Efficiency, 12, 5-17.

Harris, H. J. (2008). Conquering winter: US consumers and the cast-iron stove. Building Research \& Information, 36(4), $337-350$.

Henning, A. (2005). Climate change and energy use - the role for anthropolgical research. Anthropology Today, 21(3), 8-12.

Hyysalo, S., Pollock, N., \& Williams, R. 2019. Method matters in the social Study of technology: Investigating the biographies of artifacts and practices. Science and Technology Studies (The Finnish Society for Science and Technology Studies)

HSE. (1998). Gas safety (installation and use) regulations 1998, Health and Safety Executive.

HSE. (2013). L56 - Safety in the installation and use of gas systems and appliances- approved code of practice and guidance, Health and Safety Executive.

Huebner, G. M., McMichael, M., Shipworth, D., Shipworth, M., Durand-Daubin, M., \& Summerfield, A. J. (2014). The shape of warmth: temperature profiles in living rooms. Building Research \& Information, 43(2), 185-196.

Hughes, T. (1979). The Electrification of America: The System Builders. Technology and Culture 20, (1):124

Hughes, T. P. (1986). The seamless web: technology, science, etcetera, etcetera. Social Studies of Science, 16(2), 281-292.

Jacobs, J., Cairns, S., \& Strebel, I. (2007). 'A tall Storey...but, a fact just the same': the red road high-rise as a black box. Urban Studies, 44(2), 609-629.

Jalas, M., \& Rinkinen, J. (2016). Stacking wood and staying warm: time, temporality and housework around domestic heating systems. Journal of Consumer Culture, 61(1), 43-60.

Janda, K. (1999) Re-inscribing design work: architects, engineers, and efficiency advocates. In ECEEE 1999 Summer Study, Toulon/Hyéres, France.

Janda, K. B., \& Parag, Y. (2013). A middle-out approach for improving energy performance in buildings. Building Research \& Information, 41(1), 39-50.

Janda, K., Killip, G., \& Fawcett, T. (2014). Reducing carbon from the "middle-out": the role of builders in domestic refurbishment. Buildings, 4, 911-936.

Judson, E., Bell, S., Bulkeley, H., Powells, \& Lyon, S. (2015). The co-construction of energy provision and everyday practice: integrating heat pumps in social housing in England. Science Technology Studies, 3, 1-28.

Killip, G. (2011). Implications of an $80 \% \mathrm{CO}_{2}$ emissions reduction target for small and medium sized enterprises (SMEs) in the 
UK housing refurbishment industry. $\mathrm{PhD}$ Thesis. Oxford: Environmental Change Institute, University of Oxford.

Killip, G. (2013). Products, practices and processes: exploring the innovation potential for low-carbon housing refurbishment among small and medium-sized enterprises (SMEs) in the UK construction industry. Energy Policy, 62, 522-530.

Kuijer, L., \& Watson, M. (2017). "That's when we started using the living room": lessons from a local history of domestic heating in the United Kingdom. Energy Research \& Social Science, 28, 77-85.

Latour, B. (1987). Science in action: how to follow scientists and engineers through society. Cambridge: Harvard University Press.

Latour, B. (2005). Reassembling the social: an introduction to actor-network-theory. New York: Oxford University Press.

Latour, B., \& Woolgar, S. (1979). Laboratory life: the construction of scientific facts. New Jersey. Princeton University Press: Princeton.

Law, J. (1992). Notes on the theory of the actor-network: ordering, strategy, and heterogeneity. Systems Practice, 5(4), 379-393.

Law, J. \& Singleton, V. (2014). ANT, multplicity and policy. Critical Policy Studies, 8,(4), 379-396. https://doi. org/10.1080/19460171.2014.957056

Lutzenhiser, L. (1992). A cultural model of household energyconsumption. Energy, 17(1), 47-60.

Meier, A., Aragon, C., Peffer, T., Perry, D., \& Pritoni, M. (2011). Usability of residential thermostats: preliminary investigations. Building and Environment, 46(10), 1891-1898.

Murdoch, J. (1997). Inhuman/nonhuman/human: actor-network theory and the prospects for a nondualistic and symmetrical perspective on nature and society. Environment and Planning D: Society and Space, 15(6):731-756

Nyborg, S., \& Røpke, I. (2015). Heat pumps in Denmark-from ugly duckling to white swan. Energy Research \& Social Science, 9, 166-177.

ONS. (2014a). Trends in the United Kingdom housing market, 2014. Office for National Statistics. Available at: http://www. ons.gov.uk/ons/dcp171766 373513.pdf [Accessed 21 July 2015].

ONS. (2014b). CT0213_2011 Census - type of central heating by accommodation type - National to Lower Super Output Area. Available at: https://www.ons.gov.uk/peoplepopulation andcommunity/housing/adhocs/002528ct02132011 censustypeofcentralheatingbyaccommodationtypenationalto lowersuperoutputarea [Accessed 23 December 2019].

Orwell, G. (1945). The case for the open fire. Evening Standard. $8^{\text {th }}$ December 1945. pp.6.

Owen, A., Mitchell, G., \& Gouldson, A. (2014). Unseen influence - the role of low carbon retrofit advisers and installers in the adoption and use of domestic energy technology. Energy Policy, 73, 169-179.

Palmer, J., \& Cooper, I. (2013). United Kingdom housing energy fact file, Department of Energy \& Climate Change.

Parag, Y., \& Janda, K. (2014). More than filler: middle actors and socio-technical change in the energy system from the "middle-out". Energy Research \& Social Science, 3, 102-112.

Pickering, A. (1993). The mangle of practice: agency and emergence in the sociology of science. American Journal of Sociology, 99(3), 559-589.
Pink, S., Tutt, D., Dainty, A., \& Gibb, A. (2010). Ethnographic methodologies for construction research: knowing, practice and interventions. Building Research \& Information, 38(6), $647-659$.

Rathouse, K., \& Young, B. (2004). Domestic heating: Use of controls, Defra Market Transformation Programme.

Royston, S. (2014). Dragon-breath and snow-melt: know-how, experience and heat flows in the home. Energy Research \& Social Science, 2, 148-158.

Schiellerup, P., \& Gwilliam, J. (2009). Social production of desirable space: an exploration of the practice and role of property agents in the UK commercial property market. Environment and Planning C: Government and Policy, 27, 801-814.

Schwartz Cowan, R. (1989). The consumption junction: A proposal for research strategies in the sociology of technology. In W. Bijker, T. Hughes, \& T. Pinch (Eds.), The Social Construction of Technological Systems: New Directions in the Sociology and History of Technology (first). Cambridge: MIT Press.

Shove, E. (2003). Comfort, cleanliness \& convenience: the social organisation of normality. Oxford \& New York: Berg.

Shove, E., Walker, G., \& Brown, S. (2014). Material culture, room temperature and the social organisation of thermal energy. Journal of Material Culture, 19(2), 113-124.

Silvast, A., Williams, R., Hyysalo, S., Rommetveit, K., \& Raab, C. (2018). Who 'uses' smart grids? The evolving nature of user representations in layered infrastructures. Sustainability, 10, 3738.

Singleton, V. \& Michael, M. (1993). Actor-networks and ambivalence - General-Practitioners In The UK Cervical Screening -Program. Social Studies of Science, 23(2), 2278-28264. https://doi.org/10.1177/030631293023002001

Star, S. L. (1991). Power, technology and the phenomenology of conventions: on being allergic to onions. In J. Law (Ed.), A Sociology of Monsters: Essays on Power, Technology and Domination (pp. 26-56). London: Routledge.

Suchman, L., Blomberg, J., Orr, J., \& Trigg, R. (1999). Reconstructing technologies as social practice. The American Behavioral Scientist, 43(3), 392-408.

Wade, F., Hitchings, R., \& Shipworth, M. (2016a). Understanding the missing middlemen of domestic heating: installers as a community of professional practice in the United Kingdom. Energy Research \& Social Science, 19, 39-47.

Wade, F., Shipworth, M., \& Hitchings, R. (2016b). How installers select and explain domestic heating controls. Building Research \& Information, 45, 371-383.

Winner, L. (1993). Social constructivism: opening the black box and finding it empty. Science as Culture, 3(3), 427-452.

Woolgar, S. (1991). Configuring the user: the case of usability trails. In J. Law (Ed.), A sociology of monsters (pp. 57-102). London: Routledge.

Yaneva, A. (2008). How buildings 'surprise': the renovation of the Alte Aula in Vienn. Science Studies, 21(1), 8-28.

Publisher's note Springer Nature remains neutral with regard to jurisdictional claims in published maps and institutional affiliations. 